Jurnal_ep, Vol. 9 No. 1, Maret 2019

\title{
STUDI EVALUATIF BERBASIS MODEL CSE-UCLA TENTANG \\ EFEKTIVITAS IMPLEMENTASI PROGRAM GENDER MAINSTREAMING \\ MELALUI PEMBERDAYAAN POLWAN PADA BIDANG OPSNAL POLRI \\ DI POLRES BULELENG
}

\author{
Devi Arisuryami, Nyoman Dantes, I Gede Sudirtha, \\ Program Studi Penelitian dan Evaluasi Pendidikan, \\ Program Pascasarajana Universitas Pendidikan Ganesha \\ email kadek_devi@yahoo.co.id, \{nyoman dantes, i gede sudirtha\} \\ @ pascasarjana.undiksha.ac.id
}

\begin{abstract}
ABSTRAK
Penelitian ini bertujuan untuk mengevaluasi dan menganalisis efektifitas Implementasi Program Gender Mainstreaming Polri melalui Pemberdayaan Polwan pada bidang Opsnal Polri di Polres Buleleng Polda Bali dengan model CSA-UCLA (System Assesment, Program Planning, Program Implementation, Program Improvement dan Program Certification). Responden pada penelitian ini adalah 5 orang Kepala Satuan Kerja (Kasatker)/Atasan Langsung Polwan, 25 orang Polisi Laki-laki (Polki)/Rekan Kerja, 23 orang Polwan Polres Buleleng, 25 orang Tokoh Masyarakat dan 100 orang masyarakat di wilayah Hukum Polres Buleleng. Data dikumpulkan dengan menggunakan kuesioner, dokumentasi dan wawancara. Data dianalisis dengan analisis deskriptif kuantitatif dan diverifikasi dengan kuadran Glickman. Hasil penelitian menunjukkan bahwa secara umum berjalan dengan baik dan berada pada kuadran I yaitu terkategori efektif. Hal ini didukung oleh kepuasan masyarakat dan tokoh masyarakat di wilayah hukum Polres Buleleng yang merasa puas terhadap kinerja Polwan pada bidang opsnal Polri di Polres Buleleng. Namun terdapat hasil berbeda yang ditemukan pada penelitian yaitu efektifitas Implementasi Program Gender Mainstreaming Polri melalui Pemberdayaan Polwan pada bidang Opsnal Polri di Polres Buleleng kepada Polki/Rekan Kerja dan Polwan Polres Buleleng berada di kuadran III yaitu terkategori kurang efektif.
\end{abstract}

Kata-kata kunci: Evaluasi Program, Model CSE-UCLA, Efektivitas, Program Gender Mainstreaming, Polwan pada Bidang Opsnal Polri. 


\section{PENDAHULUAN}

Kepolisian Negara Republik Indonesia (Polri) merupakan alat negara yang mempunyai tugas pokok memelihara keamanan dan ketertiban masyarakat, melakukan penegakan hukum dan memberikan perlindungan, pengayoman, dan pelayanan kepada masyarakat. Keberadaan Polri tidak terlepas dari keberadaan sosok Polisi wanita (Polwan) itu sendiri. Polwan dibentuk tahun 1948 ketika terjadi Agresi Militer Belanda II dan merupakan profesi yang unik dan penuh tantangan. Sebagai seorang polisi, para polwan sebagian besar bertugas menghadapi kekerasan yang bermakna maskulin. Sebagai wanita, mereka diharapkan mempunyai sisi feminin dalam sikap dan tindak-tanduk baik di dalam maupun di luar pekerjaan. Suatu tantangan besar untuk menghadapi dua persepsi berlawanan tersebut.

Pelaksanaan pengarusutamaan gender (Gender Mainstreaming) di Indonesia dimulai sejak dikeluarkannya Instruksi Presiden Nomor 9 Tahun 2000 tentang Pengarusutamaan Gender dalam Pembangunan Nasional. Gender Mainstreaming dipilih sebagai strategi pembangunan nasional demi mewujudkan pembangunan yang responsif gender.

Dukungan terhadap kesetaraan Gender di tubuh Polri mendapat dukungan penuh dari Kapolri Jenderal HM Tito Karnavian. Karakter Polwan yang lemah lembut, lebih resisten terhadap budaya korupsi, memiliki kemampuan yang lebih baik dalam melayani publik, serta mempunyai sensitivitas terhadap tindak pidana yang berkaitan dengan perempuan dan anak merupakan faktor pendukung untuk menjadikan Polwan sebagai ujung tombak pelaksanaan tugas Polri sehingga pendekatannya menjadi lebih humanis dan soft tetapi tegas.

Hal ini sangat timpang dengan paradigma yang berlaku di tubuh Polri terkait penugasan polwan berdasarkan kepangkatan dan tempat tugas. Saat ini, data menunjukkan bahwa jumlah polwan yang ditugaskan di bidang pembinaan (Bin) masih sangat tinggi jika dibandingkan dengan jumlah polwan yang ditugaskan di bidang operasional. Bidang Operasional (Opsnal) Polri merupakan satuan fungsional yang mendukung kinerja organisasi Polres yang terdiri dari satuan lantas, reskrim, intelkam, res narkoba, sabhara, sat polair, tahti maupun binmas.

Berbagai terobosan kreatif telah dilakukan oleh Kapolda Bali Irjen Petrus R. Golose untuk meningkatkan citra Polri khususnya Polri Polda Bali. Salah satu terobosan yang mendapat apresiasi dari masyarakat Bali adalah pemberdayaan Polwan pada bidang opsnal Polri. Sampai saat ini belum ada peneliti yang meneliti tentang bagaimana efektifitas dari implementasi program gender mainstreaming yang dilakukan melalui pemberdayaan polwan pada bidang opsnal polri.

Penelitian ini dilakukan untuk mengetahui efektivitas implementasi program gender mainstreaming melalui pemberdayaan polwan pada bidang opsnal polri di Polres Buleleng ditinjau dari dimensi system assesment, program planning, program implementation, program 
improvement dan program certification serta kendala yang ditemukan pada Implementasi Program Gender Mainstreaming melalui Pemberdayaan Polwan di Bidang Opsnal di Polres Buleleng.

\section{METODE}

Penelitian ini adalah penelitian evaluatif yang bertujuan untuk mengukur keberhasilan implementasi suatu program. Pada penelitian ini data yang diperoleh dianalisis menggunakan pendekatan deskriptif-kuantitatif. Data dikumpulkan menggunakan kuesioner, dokumentasi dan wawancara. Berdasarkan tujuan evaluasi dan aspek-aspek yang akan dievaluasi, model evaluasi yang digunakan adalah model CSEUCLA.

Populasi penelitian ini adalah personel Polres Buleleng, masyarakat dan tokoh masyarakat di wilayah hukum Polres Buleleng. Teknik penarikan sampel pada penelitian ini menggunakan metode Purposive random sampling yaitu 5 orang Kepala Satuan Kerja (Kasatker) / Atasan Langsung Polwan, 25 orang Polisi Laki-laki (Polki) / Rekan Kerja, 23 orang Polwan Polres Buleleng, 25 orang Tokoh Masyarakat dan 100 orang masyarakat di wilayah Hukum Polres Buleleng.

Variabel yang diteliti dalam penelitian ini adalah Implementasi Program Gender Mainstreaming melalui Pemberdayaan Polwan di Bidang Opsnal di Polres Buleleng yang diukur dari lima dimensi yaitu dimensi system assesment, program planning, program implementation, program improvement dan program certification.
Kualitas skor masing-masing dimensi dihitung dengan menggunakan kategori T-Skor. Jika $\mathrm{T}>50$ adalah kategori Tinggi dan $\mathrm{T}$ $\leq 50$ adalah kategori Rendah. Untuk mengetahui hasil akhir masingmasing dimensi, baik dimensi system assesment, program planning, program implementation, program improvement dan program certification dihitung dengan menjumlahkan kategori skor Tinggi dan kategori skor Rendah. Jika jumlah kategori skor tinggi lebih banyak dari jumlah kategori skor rendah berarti hasilnya adalah Tinggi dengan simbul $\mathrm{T}$ ( $\sum$ skor $\mathrm{T}>\sum$ skor $\mathrm{R}$, maka hasilnya Tinggi), begitu sebaliknya jika jumlah kategori skor bertanda $\mathrm{T}$ lebih sedikit atau sama dengan jumlah kategori skor bertanda $\mathrm{R}$ berarti hasilnya adalah Rendah dengan simbul $\mathrm{R}\left(\sum\right.$ skor $\mathrm{T}$ $\leq \sum$ skor R, maka hasilnya Rendah). Selanjutnya dengan menggunakan katagorisasi kuadran Glickman, ditarik kesimpulan masing-masing variabel dan kualitasnya.

\section{HASIL PENELITIAN}

Ada dua hal yang diteliti dalam penelitian ini yaitu : 1) Implementasi Program Gender Mainstreaming melalui Pemberdayaan Polwan di Bidang Opsnal di Polres Buleleng yang diukur dari lima dimensi yaitu dimensi system assesment, program planning, program implementation, program improvement dan program certification, dan 2) kepuasan masyarakat dan tokoh masyarakat terhadap Pemberdayaan Polwan di Bidang Opsnal di Polres Buleleng yang terdiri dari lima dimensi yaitu tangible/wujud fisik, reliability/ kehandalan, responsiveness/daya tanggap, assurance/jaminan dan emphaty/ empati. 
Untuk mengetahui senteral semua dimensi sebagai kecenderungan data secara deskriptif, maka disajikan tendensi

Tabel 1 Deskripsi Skor Tendensi Senteral Implementasi Program Gender Mainsteaming melalui Pemberdayaan Polwan pada Bidang Opsnal Polri Dimensi AP4 untuk Kasatker / Atasan Langsung

\begin{tabular}{|c|c|c|c|c|c|c|c|}
\hline \multirow{2}{*}{ No } & $\begin{array}{c}\text { Hasil } \\
\text { Perhitungan }\end{array}$ & $\begin{array}{c}\text { System } \\
\text { Assesment (A) }\end{array}$ & $\begin{array}{c}\text { Program Planning } \\
(\mathrm{P})\end{array}$ & $\begin{array}{c}\text { Program } \\
\text { Implementation } \\
(\mathrm{P})\end{array}$ & $\begin{array}{c}\text { Program } \\
\text { Improvement (P) }\end{array}$ & $\begin{array}{c}\text { Program } \\
\text { Certification (P) }\end{array}$ & $\begin{array}{c}\text { Implementasi } \\
\text { (AP4) }\end{array}$ \\
\hline $\mathbf{1}$ & $\mathbf{2 X}$ & 131 & 232 & 155 & 198 & 154 & 870 \\
\hline 2 & $\mathbf{N}$ & 5 & 5 & 5 & 5 & 5 & 5 \\
\hline 3 & $\mathbf{M}$ & 26,20 & 46,40 & 31,00 & 39,60 & 30,80 & - \\
\hline 4 & $\mathbf{S D}$ & 1,10 & 3,65 & 0,71 & 3,78 & 1,64 & - \\
\hline 5 & $\mathbf{M o}$ & 26,20 & 46,40 & 31,00 & 39,60 & 30,80 & 174,00 \\
\hline 6 & SMi & 30,00 & 55,00 & 35,00 & 50,00 & 35,00 & 205,00 \\
\hline 7 & Mo $(\%)$ & 87,33 & 84,36 & 88,57 & 79,20 & 88,00 & 84,88 \\
\hline 8 & Max & 27 & 49 & 32 & 44 & 32 & - \\
\hline 9 & Min & 25 & 40 & 30 & 34 & 28 & - \\
\hline 10 & Kategori & Baik & Baik & Baik & Cukup Baik & Baik & Baik \\
\hline
\end{tabular}

Tabel 2 Deskripsi Skor Tendensi Senteral Implementasi Program Gender Mainsteaming melalui Pemberdayaan Polwan pada Bidang Opsnal Polri Dimensi AP4 untukPolki / Rekan Kerja Polwan

\begin{tabular}{|c|c|c|c|c|c|c|c|}
\hline \multirow{2}{*}{ No } & \multirow{2}{*}{$\begin{array}{c}\text { Hasil } \\
\text { Perhitungan }\end{array}$} & \multicolumn{5}{|c|}{ Dimensi } & \multirow{2}{*}{$\begin{array}{l}\text { Implementasi } \\
\text { (AP4) }\end{array}$} \\
\hline & & $\begin{array}{c}\text { System } \\
\text { Assesment (A) }\end{array}$ & $\begin{array}{c}\text { Program } \\
\text { Planning }(\mathrm{P})\end{array}$ & $\begin{array}{c}\text { Program } \\
\text { Implementation }(P)\end{array}$ & $\begin{array}{c}\text { Program } \\
\text { Improvement }(\mathrm{P})\end{array}$ & $\begin{array}{c}\text { Program } \\
\text { Certification }(P)\end{array}$ & \\
\hline 1 & $\Sigma x$ & 1503 & 1449 & 1021 & 1111 & 2023 & 7107 \\
\hline 2 & $\mathbf{N}$ & 25 & 25 & 25 & 25 & 25 & 25 \\
\hline 3 & M & 60,12 & 57,96 & 40,84 & 44,44 & 80,92 & - \\
\hline 4 & SD & 4,36 & 5,61 & 3,45 & 4,74 & 7,82 & - \\
\hline 5 & Mo & 60,12 & 57,96 & 40,84 & 44,44 & 80,92 & 284,28 \\
\hline 6 & SMi & 65,00 & 65,00 & 45,00 & 50,00 & 90,00 & 315 \\
\hline 7 & Mo (\%) & 92,49 & 89,17 & 90,76 & 88,88 & 89,91 & 90,25 \\
\hline 8 & Max & 65 & 65 & 45 & 50 & 90 & - \\
\hline 9 & Min & 52 & 51 & 36 & 38 & 67 & - \\
\hline 10 & Kategori & Sangat Baik & Baik & Sangat Baik & Baik & Sanga & Baik \\
\hline
\end{tabular}

Tabel 3 Deskripsi Skor Tendensi Senteral Implementasi Program Gender Mainsteaming melalui Pemberdayaan Polwan pada Bidang Opsnal Polri Dimensi AP4 untuk Polwan Polres Buleleng

\begin{tabular}{|c|c|c|c|c|c|c|c|}
\hline \multirow[b]{2}{*}{ No } & \multirow[b]{2}{*}{$\begin{array}{c}\text { Hasi } \\
\text { Perhitungan }\end{array}$} & \multicolumn{5}{|c|}{ Dimensi } & \multirow[b]{2}{*}{$\begin{array}{l}\text { Implementzai } \\
\text { (AP4) }\end{array}$} \\
\hline & & $\begin{array}{c}\text { System } \\
\text { Assesment (A) }\end{array}$ & $\begin{array}{l}\text { Program } \\
\text { Planning (P) }\end{array}$ & $\begin{array}{c}\text { Program } \\
\text { Implementafon (P) }\end{array}$ & $\begin{array}{c}\text { Program } \\
\text { Improvernent }(P)\end{array}$ & $\begin{array}{c}\text { Program } \\
\text { Cerfifcation }(P)\end{array}$ & \\
\hline 1 & $\mathbf{2 x}$ & 1330 & 1375 & 999 & 970 & 2045 & 6719 \\
\hline 2 & $\mathbf{N}$ & 23 & 23 & 23 & 23 & 23 & 23 \\
\hline 3 & $\mathbf{M}$ & 57.83 & 59.78 & $\mathbf{4 3 . 4 3}$ & 42.17 & 88.91 & - \\
\hline 4 & SD & 3.73 & 5.06 & 4.63 & 4.40 & 7.13 & - \\
\hline 5 & Mo & 57.83 & 59.78 & 43.43 & 42.17 & 88.91 & 292.13 \\
\hline 6 & Siw & 65.00 & 70.00 & 50.00 & 55.00 & 100.00 & 340 \\
\hline 7 & $\mathrm{Wo}_{\mathrm{N}}(\mathbf{\%})$ & 88.96 & 85.40 & 86.87 & 76.68 & 88.91 & 85.92 \\
\hline 8 & $\max$ & 65 & 70 & 50 & 50 & 100 & - \\
\hline 9 & $\mathrm{Wn}$ & 54 & 53 & 35 & 34 & 76 & - \\
\hline 10 & Kategori & Bak & Baik & Baik & Cukup Bak & Bak & Baik \\
\hline
\end{tabular}


Tabel 4 Deskripsi Skor Tendensi Senteral Kepuasan Masyarakat terhadap Pemberdayaan Polwan pada Bidang Opsnal Polri Dimensi Tangible, Reliability, Responsiveness, Assurance dan Emphaty

\begin{tabular}{|c|c|c|c|c|c|c|c|}
\hline \multirow[b]{2}{*}{ No } & \multirow[b]{2}{*}{$\begin{array}{l}\text { Hasil } \\
\text { Perhïtungan }\end{array}$} & \multicolumn{5}{|c|}{ Dimensi } & \multirow[b]{2}{*}{ Kepuasan } \\
\hline & & $\begin{array}{c}\text { Tangible / } \\
\text { Wujud Fisik }\end{array}$ & $\begin{array}{l}\text { Reliability / } \\
\text { Kehandatan }\end{array}$ & $\begin{array}{c}\text { Responsivenes / } \\
\text { Daya Tanggap }\end{array}$ & $\begin{array}{c}\text { Assurance / } \\
\text { Jaminan }\end{array}$ & Empaty / Empati & \\
\hline $\mathbf{1}$ & $\mathbf{z X}$ & 6557 & 3812 & 5566 & 6339 & 2937 & 25211 \\
\hline 2 & $\mathbf{N}$ & 100 & 100 & 100 & 100 & 100 & 100 \\
\hline 3 & $\mathbf{M}$ & 65.57 & 38.12 & 55.66 & 63.39 & 29.37 & - \\
\hline 4 & SD & 4.63 & 3.61 & 4.71 & 4.90 & 2.18 & - \\
\hline 5 & Mo & 65.57 & 38.12 & 55.66 & 63.39 & 29.37 & 252.11 \\
\hline 6 & SMI & 75.00 & 45.00 & 65.00 & 75.00 & 35.00 & 295 \\
\hline 7 & Mo (\%) & 87.43 & 84.71 & 85.63 & 84.52 & 83.91 & 85.46 \\
\hline 8 & Max & 75 & 45 & 65 & 75 & 35 & - \\
\hline 9 & Mîn & 54 & 28 & 46 & 46 & 24 & - \\
\hline 10 & Kategori & Puas & Puas & Puas & Puas & Puas & Puas \\
\hline
\end{tabular}

Tabel 5 Deskripsi Skor Tendensi Senteral Kepuasan Tokoh Masyarakat terhadap Pemberdayaan Polwan pada Bidang Opsnal Polri Dimensi

Tangible, Reliability, Responsiveness, Assurance dan Emphaty

\begin{tabular}{|c|c|c|c|c|c|c|c|}
\hline \multirow{2}{*}{ No } & $\begin{array}{c}\text { Hasil } \\
\text { Perhitungan }\end{array}$ & $\begin{array}{c}\text { Tangible / } \\
\text { Wujud Fisik }\end{array}$ & $\begin{array}{c}\text { Reliability / } \\
\text { Kehandalan }\end{array}$ & $\begin{array}{c}\text { Responsivenes } \\
\text { / Daya Tanggap }\end{array}$ & $\begin{array}{c}\text { Assurance / } \\
\text { Jaminan }\end{array}$ & $\begin{array}{c}\text { Empaty / } \\
\text { Empati }\end{array}$ & Kepuasan \\
\hline $\mathbf{1}$ & $\mathbf{\Sigma X}$ & 1341 & 904 & 1105 & 1345 & 640 & 5335 \\
\hline 2 & $\mathbf{N}$ & 20 & 20 & 20 & 20 & 20 & 20 \\
\hline 3 & $\mathbf{M}$ & 67,05 & 45,20 & 55,25 & 67,25 & 32,00 & - \\
\hline 4 & SD & 4,57 & 2,73 & 3,57 & 4,74 & 2,00 & - \\
\hline 5 & Mo & 67,05 & 45,20 & 55,25 & 67,25 & 32,00 & 266,75 \\
\hline 6 & SMi & 75,00 & 50,00 & 60,00 & 75,00 & 35,00 & 295 \\
\hline 7 & Mo (\%) & 89,40 & 90,40 & 92,08 & 89,67 & 91,43 & 90,42 \\
\hline 8 & Max & 75 & 50 & 60 & 75 & 35 & - \\
\hline 9 & Min & 60 & 42 & 48 & 55 & 29 & - \\
\hline 10 & Kategori & Puas & Sangat Puas & Sangat Puas & Puas & Sangat Puas & Sangat Puas \\
\hline
\end{tabular}

Untuk mengetahui Efektifitas Implementasi Program Gender Mainstreamingmelalui Pemberdayaan Polwan di Bidang Opsnal di Polres Buleleng yang diukur dari lima dimensi yaitu dimensi system assesment, program planning, program implementation, program improvement dan program certification digunakan katagorisasi kuadran Glickman.

Tabel 6 Rangkuman Hasil Implementasi Program Gender MainstreamingPolri melalui Pemberdayaan Polwan pada bidang Opsnal Polri di Polres Buleleng dari Model Evaluasi CSE - UCLA

\begin{tabular}{|c|l|c|c|c|}
\hline \multirow{2}{*}{ No } & \multirow{2}{*}{ Dimensi } & $\begin{array}{c}|c| \\
\text { Kasatker / } \\
\text { Atasan } \\
\text { Langsung }\end{array}$ & $\begin{array}{c}\text { Polki / } \\
\text { Rekan } \\
\text { Kerja }\end{array}$ & $\begin{array}{c}\text { Polwan } \\
\text { Polres } \\
\text { Buleleng }\end{array}$ \\
\hline 1 & System Assesment $(\mathrm{A})$ & $\mathrm{T}$ & $\mathrm{R}$ & $\mathrm{R}$ \\
\hline 2 & Program Planning $(\mathrm{P})$ & $\mathrm{T}$ & $\mathrm{R}$ & $\mathrm{R}$ \\
\hline 3 & Program Implementation $(\mathrm{P})$ & $\mathrm{T}$ & $\mathrm{R}$ & $\mathrm{T}$ \\
\hline 4 & Program Improvement $(\mathrm{P})$ & $\mathrm{T}$ & $\mathrm{T}$ & $\mathrm{R}$ \\
\hline 5 & Program Certification $(\mathrm{P})$ & $\mathrm{T}$ & $\mathrm{T}$ & $\mathrm{T}$ \\
\hline
\end{tabular}


Dari tabel di atas diketahui bahwa efektifitas implementasi program gender mainstreaming melalui pemberdayaan polwan pada bidang opsnal polri di Polres Buleleng untuk kasatker/atasan langsung menunjukkan hasil dengan kecenderungan arah T-Skor dalam CSE-UCLA (T,T,T,T,T) berada pada kuadran I yaitu terkategori efektif. Efektifitas implementasi program gender mainstreaming melalui pemberdayaan polwan pada bidang opsnal polri di Polres Buleleng untuk Polki/rekan kerja menunjukkan hasil dengan kecenderungan arah T-Skor dalam CSE-UCLA (R,R,R,T,T) berada pada kuadran III yaitu terkategori kurang efektif. Sedangkan Efektifitas implementasi program gender mainstreaming melalui pemberdayaan polwan pada bidang opsnal polri di Polres Buleleng untuk Polwan Polres Buleleng menunjukkan hasil dengan kecenderungan arah T-Skor dalam CSE-UCLA (R,R,T,R,T) berada pada kuadran III yaitu terkategori kurang efektif.

Secara umum Implementasi Program Gender Mainstreaming melalui Pemberdayaan Polwan pada bidang Opsnal Polri di Polres Buleleng berjalan dengan Baik. Namun penelitian menunjukkan

\section{PEMBAHASAN}

Pengujian pada responden masyarakat di wilkum Polres Buleleng menunjukkan bahwa dilihat dari dimensi Tangible/Wujud fisik, Reliability/Kehandalan,

Responsivenes/Daya Tanggap, Assurance/Jaminan dan

Empaty/Empati, masyarakat merasa puas terhadap kinerja Polwan pada bidang opsnal Polri di Polres Buleleng. Hal tersebut terdapat beberapa hal yang menyebabkan pemberdayaan polwan pada bidang opsnal polri di Polres Buleleng belum maksimal. Adapun kendala dimaksud adalah :

1. Belum adanya Kebijakan
Program dan Anggaran yang
jelas untuk Gender
Mainstreaming di kepolisian.

2. Pemahaman konseptual di internal Polri secara umum memperlihatkan lemahnya pemahaman Gender Mainstreaming. Hal ini menjadi salah satu alasana mengapa Polwan ditempatkan di bidang Bin, karena Polwan dianggap lebih menonjol di bidang Administrasi dibandingkan dengan operasional karena Polwan dianggap lebih teliti;

3. Menugaskan Polwan pada kasus berat dan tugas lapangan lainnya, dirasa kurang efektif karena banyak batasan dan karena alasan kodrat, etika dan normatif ;

4. Banyak dispensasi yang diberikan kepada Polwan terutama ketika sudah menikah dan hamil, sehingga kinerja Polwan dianggap tidak maksimal.

mengimplikasikan bahwa semakin besar kesempatan yang diberikan kepada Polwan untuk berkiprah pada bidang opsnal Polri maka semakin membuka peluang bagi aparat kepolisian membangun citra yang dapat dipercaya oleh masyarakat. Polisi yang dipercaya adalah tangga awal untuk merebut hati masyarakat.

Masyarakat mengapresiasi positif keberadaan Polwan Polres Buleleng yang bertugas pada bidang 
opsnal Polri. Hasil penelitian terhadap Tokoh Masyarakat Buleleng juga menunjukkan hasil yang sama. Para tokoh masyarakat (Toga,Tomas,Todat) menilai positif Polwan berada ditengah-tengah masyarakat. Ditinjau dari dimensi Tangible/Wujud fisik responden merasa puas terhadap kinerja Polwan Polres Buleleng yang bertugas di bidang opsnal polri. Ditinjau dari dimensi Reliability/Kehandalan fisik responden merasa sangat puas terhadap kinerja Polwan Polres Buleleng yang bertugas di Bidang Opsnal Polri. Ditinjau dari dimensi Responsivenes/Daya Tanggap responden merasa sangat puas terhadap kinerja Polwan Polres Buleleng yang bertugas di Bidang Opsnal Polri. Ditinjau dari dimensi Assurance/Jaminan responden merasa puas terhadap kinerja Polwan Polres Buleleng yang bertugas di Bidang Opsnal Polri. Sedangkan ditinjau dari dimensi Empaty/Empati responden merasa merasa sangat puas terhadap kinerja Polwan Polres Buleleng yang bertugas di Bidang Opsnal Polri. Peningkatan peran Polwan pada berbagai satuan dan fungsi diperlukan karena kehadirannya memberikan perubahan dan warna baru pada pekerjaan baru dan gaya pemolisian. Hal ini didukung oleh citra Polwan yang positif dan adanya tuntutan peningkatan profesionalisme.

Respon positif ini tidak terlepas dari usaha gigih para Polwan Polres Buleleng untuk merengkuh hati masyarakat. Polisi Wanita mampu memahami karakter masyarakat, menaruh simpati dan empati yang tinggi terhadap penderitaan masyarakat, serta betulbetul menempatkan diri sebagai pengayom dan pelayan masyarakat.
Polisi Wanita mampu menjaga keamanan masyarakat secara umum.

Dukungan terhadap Polwan yang bertugas pada bidang opsnal Polri ditunjukkan oleh Kapolda Bali Irjen Pol Petrus R. Golose. Hal ini ditunjukkan dengan diberikannya fasilitas berupa sepeda motor kepada Bhabinkamtibmas Polwan di Jajaran Polda Bali. Kapolda Bali berharap agar kehadiran Polwan sebagai Bhabinkamtibmas dapat memberi kesejukan bagi masyarakat, sehingga situasi Kamtibmas akan selalu aman dan kondusif.

Mendukung hasil yang diperoleh diatas, analisis Glickman terhadap Efektifitas Implementasi Program Gender Mainstreaming melalui pemberdayaan Polwan pada bidang Opsnal Polri menunjukkan hasil sangat efektif. Hasil pengujian terhadap jawaban responden Kasatker / Atasan Polwan menunjukkan bahwa implementasi program Gender Mainstreaming melalui pemberdayaan Polwan pada bidang Opsnal Polri yang dilaksanakan di Polres Buleleng dengan kecenderungan $\mathrm{A}=$ tinggi, $\mathrm{P}$ = tinggi, $\mathrm{P}=$ tinggi, $\mathrm{P}=$ tinggi dan $\mathrm{P}$ $=$ tinggi. Ini berarti Efektifitas Implementasi Program Gender Mainstreaming melalui pemberdayaan Polwan pada bidang Opsnal Polri berada pada kuadran I yakni kategori efektif.

Hal berbeda ditunjukkan dari analisis Glickman terhadap Efektifitas Implementasi Program Gender Mainstreaming melalui pemberdayaan Polwan pada bidang Opsnal Polri dengan responden Polki/Rekan Kerja dan responden Polwan Polres Buleleng. Hasil pengujian terhadap jawaban responden baik dari Polki / Rekan Kerja dan Polwan Polres Buleleng 
sama-sama menunjukkan bahwa Efektifitas Implementasi Program Gender Mainstreaming melalui pemberdayaan Polwan pada bidang Opsnal Polri berada pada kuadran III yakni terkategori kurang efektif.

\section{Efektifitas Implementasi}

Program Gender Mainstreaming melalui pemberdayaan Polwan pada bidang Opsnal Polri dengan responden Polki / Rekan Kerja dan responden Polwan Polres Buleleng sama-sama menunjukkan dimensi System Assesment dan Program Planning yang rendah.

$$
\text { Dari dimensi System }
$$

Assesment Implementasi Program Gender Mainstreaming melalui pemberdayaan Polwan pada bidang Opsnal Polri menunjukkan hasil yang rendah, hal ini disebabkan : 1) Visi dan Misi Polres Buleleng yang kurang diketahui oleh personel Polres Buleleng, hal ini disebabkan karena personel Polres Buleleng kurang aware (sadar / peduli) terhadap kegiatan dan sosialisasi dari pihak perencana Polres kepada personel di jajaran; 2) Personel Polres Buleleng belum banyak yang mengetahui tentang Program Gender Mainstreaming di tubuh Polri. Sejauh ini Polres Buleleng telah melakukan beberapa bentuk implementasi program untuk menunjukkan perhatiannya pada Gender Mainstreaming di lingkungan Polri, meskipun belum terlaksana dengan baik. Hal ini disebabkan oleh masih lemahnya pemahaman terhadap norma hukum nasional dan internasional dan rendahnya kebijakan operasional pendukung kebijakan ini. Dukungan politik pimpinan Polri ini tidak dibarengi dengan pemahaman yang baik tentang bagaimana Gender Mainstreaming itu akan dilakukan sesuai dengan Inpres Nomor 9 Tahun 2000; dan 3) Upaya Polres Buleleng dalam menggandeng stakeholder untuk mendukung pelaksanaan program Gender Mainstreaming melalui pemberdayaan Polwan pada bidang Opsnal Polri masih berdasarkan proyek tanpa mengakitkannya dengan keseluruhan program Polri. Sampai saat ini upaya Polres Buleleng dalam menggandeng stakeholder masih sebatas pada kegiatan sosialisasi belum menghasilkan aksi konkret. Konstruksi sosial peran gender telah memposisikan perempuan untuk melakukan pekerjaan reproduksi sebagai kerja-kerja utama perempuan dan yang dianggap kodrati. Peran reproduksi ini dilekatkan sebagai identitas utama perempuan yang kemudian mengaburkan fakta multi identitas perempuan yang terbentuk dari status sosial, kelas sosial ekonomi, etnisitas, pekerjaan. Karena itu, perlu dilakukan aksi konkret antara Polri (dalam hal ini Polres Buleleng) dan stakeholder dalam pengintegrasian gender dan inklusi sosial sehingga aspirasi, kebutuhan dan pengalaman yang berbeda dari masing masing pihak dapat direspon dengan tepat dan mampu berkontribusi secara maksimal terhadap tujuan pembangunan.

\section{Dari dimensi program} planning Implementasi Program Gender Mainstreaming melalui pemberdayaan Polwan pada bidang Opsnal Polri menunjukkan hasil yang rendah, hal ini disebabkan : 1) Belum tersedianya pos anggaran yang jelas untuk Program Gender Mainstreaming di Polres Buleleng. Sampai saat ini kebijakan terkait anggaran program masih dibebankan pada Duk Ops Polres Buleleng dan 
belum tercantum pada DIPA Polres Buleleng, 2) Sarana dan Prasarana dalam mendukung pelaksanaan program Gender Mainstreaming belum tersedia di Polres Buleleng, 3) Polres Buleleng tidak memiliki piranti atau tools untuk melaksanakan monitoring dan evaluasi terhadapat pelaksanaan program Gender Mainstreaming, karena sampai saat ini monitoring dan evaluasi yang dilakukan oleh satuan atas namun belum menyentuh Polres Buleleng, 4) Monitoring dilaksanakan oleh Tim Mabes Polri bersifat isidentil dan tidak kontinyu serta tidak ada evaluasi lebih lanjut terhadap hasil monitoring, sehingga kelemahan-kelemahan yang terjadi dalam Implementasi program Gender Mainstreaming tidak dapat ditanggulangi secara cepat dan tepat. Kelambanan program Gender Mainstreaming di lingkungan Polri disebabkan oleh dominannya budaya patriakal dalam institusi Polri, walaupun Polri tetap menyatakan bahwa institusi ini sudah responsif gender jauh sebelum istilah Gender Mainstreaming diperkenalkan. Kebijakan pemerintah ini juga belum diitegrasikan kedalam seluruh program di Polri dan masih terfokus pada sosialisasi kepada anggota Polri di lingkungan Markas Besar Polri dan Polda.

Sementara itu, efektifitas implementasi program gender mainstreaming melalui pemberdayaan polwan pada bidang opsnal polri dengan responden Polki/Rekan Kerja menunjukkan dimensi program implementation yang rendah, hal ini disebabkan karena masih banyak Polisi laki-laki yang ragu atas kemampuan (terutama fisik) Polwan untuk diberikan tugas atau kasus berat maupun tugas operasional. Penempatan Polwan dianggap kurang efektif karena polwan memiliki banyak batasan sehingga memerlukan personel pendukung untuk pendampingan dalam tugas. Banyaknya dispensasi yang diberikan kepada Polwan terutama ketika sudah menikah dan hamil, menyebabkan munculnya pendapat bahwa kinerja Polwan tidak maksimal. Selain itu, tidak terdapatnya peningkatan jumlah personel Polwan secara periodik menyebabkan kurangnya regenerasi Polwan di Polres Buleleng. Hal ini berimbas pada implementasi program gender mainstreaming melalui pemberdayaan Polwan pada bidang Opsnal Polri dilaksanakan hanya berdasarkan kebijakan pimpinan saat itu dan tidak berkesinambungan.

Efektifitas implementasi program gender mainstreaming melalui pemberdayaan polwan pada bidang opsnal polri dengan responden Polwan Polres Buleleng menunjukkan dimensi program improvement yang rendah disebabkan karena 1) Keterbatasan jumlah personel Polwan. Data menunjukkan bahwa jumlah personel Polwan yang bertugas di Polres Buleleng tidak mengalami peningkatan malah terdapat penurunan jumlah personel Polwan Bintara Muda yang bertugas di Polres Buleleng dikarenakan adanya mutasi ke satker Mabes/Polda Bali. Hal ini akan berimplikasi pada efektifitas Implementasi Program Gender Mainstreaming melalui pemberdayaan Polwan pada bidang Opsnal Polri tidak mengalami peningkatan yang berarti, dan 2) personel Polwan Polres Buleleng yang diberdayakan pada bidang opsnal Polri di dominasi oleh Polwan 
Bintara Muda berpangkat Bripda Briptu, sehingga mereka belum memiliki jam terbang yang cukup. Pengalaman kerja yang masih relatif sedikit masih membutuhkan proses agar Polwan dimaksud memiliki rasa percaya diri (self confidence), memiliki kemampuan dalam mengelola (organize) dan memiliki kemampuan dalam mengambil keputusan (decision making) dalam melaksanakan tugas opsnal Polri.

\section{SIMPULAN DAN SARAN}

\section{Berdasarkan hasil penelitian dan analisis data diatas, dapat disimpulkan beberapa hal sebagai berikut.}

1. Hasil penelitian terhadap efektifitas implementasi program gender mainstreaming melalui pemberdayaan polwan pada bidang opsnal polri untuk Kasatker/atasan langsung berada pada kuadran I yakni terkategori efektif.

2. Hasil penelitian terhadap efektifitas implementasi program gender mainstreaming melalui pemberdayaan polwan pada bidang opsnal polri untuk Polki / Rekan Kerja berada pada kuadran III yakni terkategori kurang efektif.

4. Hasil penelitian terhadap efektifitas implementasi program gender mainstreaming melalui pemberdayaan polwan pada bidang opsnal polri untuk Polwan Polres Buleleng berada pada kuadran III yakni terkategori kurang efektif:

5. Secara umum Implementasi Program Gender Mainstreaming melalui pemberdayaan Polwan pada bidang Opsnal Polri di Polres Buleleng dapat berjalan
Hambatan yang ditemui dilapangan terkait implementasi program gender mainstreaming melalui pemberdayaan polwan pada bidang opsnal polri dapat dikikis melalui pendekatan berkelanjutan. Kontinuitas dan dukungan lebih lanjut diharapkan tidak berhenti pada kebijakan pimpinan saat ini, mengingat program ini baru memasuki masa-masa awal implementasi.

dengan baik. Dari penelitian yang dilakukan, terdapat beberapa hal yang menyebabkan Pemberdayaan Polwan pada bidang Opsnal Polri belum maksimal.

Berdasarkan implikasi dan simpulan yang dikemukakan di atas, maka dapat diajukan beberapa saran sebagai berikut.

1. Agar Kapolres Buleleng tetap melakukan monitoring dan evaluasi terkait Implementasi Program Gender Mainstreaming sehingga program dapat berjalan secara berkesinambungan dan kinerja Polwan semakin meningkat;

2. Agar dilakukan aksi konkret antara Polres Buleleng dan stakeholder terkait Implementasi Program Gender Mainstreaming demi keberlanjutan dan kesinambungan program;

3. Sosialisasi Program Gender Mainstreaming di tubuh perlu dilaksanakan secara berkesinambungan ke masingmasing jajaran Polres Buleleng, sehingga personel Polri sampai dengan tingkat Polsek/Sub Sektor mengetahui apa, bagaimana dan implementasi dari Program Gender Mainstreaming; 
4. Tingginya kepuasan Masyarakat dan Tokoh Masyarakat di wilkum Polres menunjukkan bahwa kinerja Polwan Polres Buleleng yang bertugas di bidang Opsnal Polri dinilai baik dan masyarakat menginginkan

\section{DAFTAR REFERENSI}

Alkin, Marvin C. "Evaluation Theory Development." CSEUCLA Evaluation Comment, Vol. 2, No. 1, 1969 : 1-11.

Anas Sudijono. 2011. Pengantar Evaluasi Pendidikan.Cetakan 10.Jakarta: Rajagrafindo.

Arikunto, Suharsimi dan Jabar CSA, 2008. Evaluasi Program Pendidikan: Pedoman Teoritis Praktis Bagi Mahasiswa dan Praktisi Pendidikan (Edisi Kedua). Jakarta : Bumi Aksara.

Dantes, Nyoman. 2012. Metodologi Penelitian. Yogyakarta : Andi Ofset.

Dewa Gede Hendra Divayana. 2016. "Evaluasi Program Perpustakaan Digital Berbasis Sistem Pakar pada Universitas Teknologi Idonesia”. Disertasi. Program Pasca Sarjana Universitas Negeri Jakarta.

D.G.H. Divayana, D.B. Sanjaya, A.A.I.N. Marhaeni, and I.G. Sudirtha, "CIPP Evaluation Model Based on Mobile Phone in Evaluating The Use of Blended Learning Platforms at Vocational
Polwan berada ditengah-tengah masyarakat. Hal ini bisa menjadi pertimbangan Pimpinan pada pola kebijakan penempatan personel Polwan di Polres Buleleng;

Schools in Bali", Journal of Theoretical and Applied Information Technology, Vol. 95. No 9, 2017, pp. 1983-1995.

D.G.H. Divayana, Nyoman Dantes, A.A.I.N. Marhaeni, Ida Bagus Putu Aryana, and Wardani Rahayu, "Evaluation of Blended Learning Process of Expert System Course Program By Using CSEUCLA Model Based on Mobile Technology", Journal of Theoretical and Applied Information Technology, Vol. 95. No 13, 2017, pp. 19831995.

Direktorat Kependudukan dan Pemberdayaan Perempuan Bappenas.2006.Evaluasi

Pengarusutamaan Gender di Sembilan Sektor Pembangunan Tahun 2006.Jakarta : Bappenas.

Glickman, C.D., Gordon, S.P., \& Ross-Gordon, J.M. 2000.Supervition and Instructional Leadership. Needham Heights, MA : Allyn \& Bacon.

Gregory, Robert J. 2000. Psychological Testing : History, Principles, and Applications. USA : Allyn \& Bacon Inc. 
Koyan, I Wayan. 2005. Evaluasi Program Pendidikan. Singaraja. Undiksha Pers.

Koyan, I Wayan. 2012. Statistik Pendidikan Teknik Analisis Data Kuantitatif. Singaraja: Universitas Pendidikan Ganesha Press.

Mabes Polri. 1999. Buku Biru Reformasi Polri. Jakarta : Mabes Polri.

Marhaeni, A.A.I.N. 2007. Evaluasi Program Pendidikan. Singaraja: Undiksha Pers.

Marhaeni, A.A.I.N. 2008. Perkembangan Perempuan, Studi Kritik,dan
Gagasan Sebuah Perspektif untuk Studi Gender ke Depan.Jurnal Piramida dalam ejournal.unud.ac.id. diakses 25 Oktober2012 .

Rizka Yulidasari, 2017. “Analisis Pembelajaran PJOK Menggunakan Pendekatan CSE-UCLA Evaluation Model'. Tesis. Program Pasca Sarjana Universitas Negeri Malang.

Siska Andriani, 2015. "Evaluasi CSE-UCLA pada Studi Proses Pembelajaran Matematika". Tesis. Al-Jabar : Jurnal Pendidikan Matematika Vol. 6, No. 2, 2015. 